\title{
Mechanical deterioration underlies malignant behavior of aneurysmal human ascending aorta
}

\author{
George Koullias, MD, ${ }^{a}$ Raj Modak MD, ${ }^{b}$ Maryann Tranquilli, RN, ${ }^{a}$ Dimitris P. Korkolis, MD, ${ }^{a}$ Paul Barash, MD, ${ }^{a}$ \\ and John A. Elefteriades, MD
}

Additional material is available online. $\widetilde{\vartheta}$
From the Sections of Cardiothoracic Surgery and Cardiothoracic Anesthesia, ${ }^{a}$ Yale University School of Medicine, ${ }^{\mathrm{b}}$ New Haven, Conn.

Received for publication Oct 31, 2004; revisions received Jan 23, 2005; accepted for publication Feb 10, 2005.

Address for reprints: John A. Elefteriades, MD, Section of Cardiothoracic Surgery, 121 FMB, 333 Cedar St, New Haven, CT 06510 (E-mail: john.elefteriades@yale.edu).

J Thorac Cardiovasc Surg 2005;130:677-83

$0022-5223 / \$ 30.00$

Copyright $\odot 2005$ by The American Association for Thoracic Surgery

doi:10.1016/j.jtcvs.2005.02.052
Objective: The human ascending aorta becomes markedly prone to rupture and dissection at a diameter of $6 \mathrm{~cm}$. The mechanical substrate for this malignant behavior is unknown. This investigation applied engineering analysis to human ascending aortic aneurysms and compared their structural characteristics with those of normal aortas.

Methods: We measured the mechanical characteristics of the aorta by direct epiaortic echocardiography at the time of surgery in 33 patients with ascending aortic aneurysm undergoing aortic replacement and in 20 control patients with normal aortas undergoing coronary artery bypass grafting. Six parameters were measured in all patients: aortic diameter in systole and diastole, aortic wall thickness in systole and diastole, and blood pressure in systole and diastole. These were used to calculate mechanical characteristics of the aorta from standard equations. Aortic distensibility reflects the elastic qualities of the aorta. Aortic wall stress reflects the disrupting force experienced within the aortic wall. Incremental elastic modulus indicates loss of elasticity reserve.

Results: Aortic distensibility falls to extremely low levels as aortic dimension rises toward $6 \mathrm{~cm}\left(3.02 \mathrm{~mm} \mathrm{Hg}^{-1}\right.$ for small aortas versus $1.45 \mathrm{~mm} \mathrm{Hg}^{-1}$ for aortas larger than $5 \mathrm{~cm}, P<.05$ ). Aortic wall stress rises to $157.8 \mathrm{kPa}$ for the aneurysmal aorta, compared with $92.5 \mathrm{kPa}$ for normal aortas. For 6-cm aortas at pressures of $200 \mathrm{~mm}$ $\mathrm{Hg}$ or more, wall stress rises to $857 \mathrm{kPa}$, nearly exceeding the known maximal tensile strength of human aneurysmal aortic wall. Incremental elastic modulus deteriorates $(1.93 \pm 0.88 \mathrm{MPa}$ vs $1.18 \pm 0.21 \mathrm{MPa}, P<.05)$ in aneurysmal aortas relative to that in normal aortas.

Conclusion: The mechanical properties of the aneurysmal aorta deteriorate dramatically as the aorta enlarges, reaching critical levels associated with rupture by a diameter of $6 \mathrm{~cm}$. This mechanical deterioration provides an explanation in engineering terms for the malignant clinical behavior (rupture and dissection) of the aorta at these dimensions. This work adds to our fundamental understanding of the biology of aortic aneurysms and promises to permit future application of engineering measurements to supplement aneurysm size in clinical decision making in aneurysmal disease.

$\mathrm{P}$ revious reports from our research group, as well as others, have shed light on the natural history of thoracic aortic aneurysm and dissection. ${ }^{1}$ We can now predict, on a fairly rigorous statistical basis, the yearly likelihood of dissection or rupture according to the diameter of the thoracic aneurysm. ${ }^{2}$ Specifically, when the aorta reaches $6 \mathrm{~cm}$ in diameter, the yearly risk of rupture, dissection, or death rises dramatically-to a striking $14.1 \%$ per year. $^{2}$

Pioneering work by Toutouzas and colleagues ${ }^{3}$ has applied engineering principles to elucidate the mechanical properties of the normal aorta, including changes 
associated with sex, hypertension, and age. The aorta, we are realizing, is "much more than a tube" 4 -more complex than a passive, hollow conduit for delivery of blood. Rather, the aorta, through its elastic properties, actively participates in the propulsion of the blood and interplays elegantly with the left ventricle in a "game of catch" with the stroke volume. ${ }^{5-7}$ A properly functioning aorta actually unloads the left ventricle. ${ }^{8}$ In the abdominal aorta, mechanical properties in disease states are beginning to be explored..$^{9,10}$ As yet, the powerful techniques of mechanical analysis have not been widely applied to study of the thoracic aorta.

This study analyzed the mechanical properties of the aneurysmal ascending aorta in vivo in human patients and compared the findings with the mechanical characteristics of normal (nonaneurysmal) aortas. Our actual in vivo measurements distinguish this study from theoretical engineering models and from ex vivo investigations on resected tissue. All measurements were taken by direct epiaortic echocardiography done at the time of aortic replacement (subjects) or nonaneurysm heart surgery (controls).

As will be seen, a full profile of the mechanical properties of the aorta can be gleaned by measuring six specific physical characteristics: blood pressure (systolic and diastolic), aortic diameter (systolic and diastolic), and thickness of the aortic wall (systolic and diastolic). In general, the aortic diameter increases during systole (aorta enlarges under increased distensile pressure), and the thickness of the aortic wall decreases during systole (aortic wall thins under increased distensile pressure). ${ }^{7}$

From these six measurements, a complete mechanical profile of the aorta can be constructed. The engineering characteristics that can be calculated are aortic wall distensibility, aortic wall stress, and incremental elastic modulus $\left(\mathrm{E}_{\text {inc }}\right)$.

This study was designed to use data obtainable from intraoperative echocardiography to compute key mechanical properties of ascending aortic aneurysms. These data, obtained by epiaortic echocardiography, were compared with similar data from normal ascending aortas serving as controls. The aims of this investigation were as follows: (1) to calculate mechanical properties of the aneurysmal aortic wall, (2) to evaluate the evolution of these values as aneurysm diameter increases, (3) to explore the relation of calculated aortic wall stress to the maximum aneurysm wall strength, and (4) to estimate at what aneurysm diameter the applied stress approaches the intrinsic wall strength, leading to high probability of rupture or dissection.

Such analysis could lead to greater understanding of the pathophysiology of aortic diseases. It is conceivable that increased understanding of the deterioration of mechanical properties of the aneurysmal aorta could lead to better echocardiographically based prediction of the catastrophic events of rupture and dissection than is possible today on the basis of aneurysm size alone.

\section{Methods \\ Patient Group}

All patients were operated on at Yale-New Haven Hospital between April 2002 and December 2003. The study was preceded by a 3-month period during which the epiaortic echocardiography technique was standardized by development of a specific routine and extensive repetition, which resulted in high data reproducibility. One group ("normal" aortas) consisted of 20 patients with coronary artery disease who underwent coronary artery bypass grafting. The second group consisted of 33 patients who underwent elective ascending aortic aneurysm resection. Patients with a documented diagnosis of Marfan syndrome or evidence of dissection or aortitis of any etiology were excluded. Our aneurysm group consisted of patients with aneurysms caused by atherosclerosis or medial degeneration. This study was approved by the human investigation committee of Yale University. For study design purposes, the aneurysm patient group was afterward divided into four different subgroups according to aneurysm diameter: group 1, diameter less than $4 \mathrm{~cm}(\mathrm{n}=12)$; group 2 , diameter 4 to $5 \mathrm{~cm}(\mathrm{n}$ $=13)$; group 3 , diameter 5 to $6 \mathrm{~cm}(\mathrm{n}=5)$; and group 4 , diameter greater than $6 \mathrm{~cm}(\mathrm{n}=3)$.

There were no significant differences between the control and aneurysm groups with respect to age $(64 \pm 2.61$ years vs $64.8 \pm$ 4.7 years, respectively, $P$ not significant), sex (female/male ratio $6: 14$ vs $4: 29, P$ not significant), heart rate $(72 \pm 8.4$ beats $/ \mathrm{min}$ vs $69 \pm 7.2$ beats $/ \mathrm{min}, P$ not significant), and either systolic or diastolic blood pressure (systolic $107.1 \pm 2.45 \mathrm{~mm} \mathrm{Hg}$ vs $108 \pm$ $5.2 \mathrm{~mm} \mathrm{Hg}$, diastolic $59 \pm 1.67 \mathrm{~mm} \mathrm{Hg}$ vs $61.5 \pm 3.84 \mathrm{~mm} \mathrm{Hg}$, both $P$ not significant) during the performance of echocardiography.

\section{Epiaortic Echocardiography}

After median sternotomy and pericardiotomy and before cannulation, a 6- to $15-\mathrm{MHz}$ echocardiographic probe (Phillips model 21390A, Andover, Mass) with added ultrasonographic gel was inserted into a sterile sheath. The probe was connected to a standard ultrasonographic station (Phillips series 5500). A cushion constructed from a surgical glove finger filled with normal saline solution was used as an echocardiographic interface between the probe and the aneurysm. On application of the probe, the peaksystolic and end-diastolic diameters, as well as the peak-systolic and end-diastolic wall thicknesses, were recorded under continuous synchronous blood pressure monitoring. To maximize accuracy, measurements were made independently for three separate cardiac cycles. The aorta was visualized first in 2-dimensional mode. When optimal aortic cross-sections had been identified, the images were switched to M-mode. Measurements were taken in triplicate from the M-mode display with the distance cursor. In 15 of the 33 patients with aneurysms, measurements were taken both at the "neck" (or narrow zone) and the "belly" (or widest accessible portion) of the aneurysm. It should be noted that the diameters measured at the belly may fall short of the largest known diameter of the aneurysm if part of the aneurysm is inaccessible to direct application of the echocardiographic probe (especially true in the case of annuloaortic ectasia, in which the immediate supra- 
TABLE 1. Mechanical parameters in normal ascending aortas and ascending aortic aneurysms

\begin{tabular}{lcccccc}
\hline \multicolumn{1}{c}{ Parameter } & $\begin{array}{c}\text { Normal } \\
(\mathbf{n}=\mathbf{2 0})\end{array}$ & $\begin{array}{c}\text { All aneurysms } \\
(\mathbf{n}=\mathbf{3 3})\end{array}$ & $\begin{array}{c}\text { Aneurysms } \\
<\mathbf{4} \mathbf{~ c m} \\
(\mathbf{n}=\mathbf{1 2})\end{array}$ & $\begin{array}{c}\text { Aneurysms } \\
\mathbf{4 - 5} \mathbf{~ c m} \\
(\mathbf{n}=\mathbf{1 3})\end{array}$ & $\begin{array}{c}\text { Aneurysms } \\
\mathbf{5 - 6} \mathbf{~ c m} \\
(\mathbf{n}=\mathbf{5})\end{array}$ & $\begin{array}{c}\text { Aneurysms } \\
>\mathbf{6} \mathbf{~ c m} \\
(\mathbf{n}=\mathbf{3})\end{array}$ \\
\hline Mean end-systolic diameter (cm) & $2.88 \pm 0.3$ & $4.483 \pm 1.04$ & $3.6 \pm 0.12$ & $4.53 \pm 0.18$ & $5.35 \pm 0.16$ & $6.72 \pm 0.67$ \\
Mean end-diastolic diameter (cm) & $2.723 \pm 0.38$ & $4.093 \pm 0.98$ & $3.42 \pm 0.14$ & $4.37 \pm 0.17$ & $5.13 \pm 0.19$ & $6.518 \pm 0.52$ \\
Percentage variation in diameter (\%) & 6.745 & 4.85 & 6.28 & 5.56 & 4.31 & 2.92 \\
Mean end-systolic wall thickness (cm) & $0.2275 \pm 0.02$ & $0.245 \pm 0.019$ & $0.264 \pm 0.021$ & $0.251 \pm 0.02$ & $0.242 \pm 0.03$ & $0.164 \pm 0.025$ \\
Mean end-diastolic wall thickness (cm) & $0.256 \pm 0.02$ & $0.252 \pm 0.017$ & $0.279 \pm 0.019$ & $0.261 \pm 0.017$ & $0.266 \pm 0.012$ & $0.166 \pm 0.035$ \\
Distensibility (mm Hg ${ }^{-1}$ ) & $2.499 \pm 0.49$ & $2.498 \pm 0.35$ & $3.02 \pm 0.595$ & $2.616 \pm 0.654$ & $1.91 \pm 0.34$ & $0.81 \pm 0.32$ \\
Wall stress (kPa at 85-100 mm Hg) & $92.51 \pm 6.35$ & $157.8 \pm 18.76$ & $108.5 \pm 12.72$ & $150.6 \pm 13.26$ & $177.39 \pm 45.7$ & $376.9 \pm 146.6$ \\
$\mathrm{E}_{\text {inc }}$ (MPa) & $1.18 \pm 0.21$ & $1.93 \pm 0.32$ & $0.908 \pm 0.16$ & $1.535 \pm 0.26$ & $2.01 \pm 0.37$ & $6.42 \pm 0.53$ \\
\hline
\end{tabular}

All data except percentage variation in diameter are mean \pm SEM. $E_{\text {inc }}$ Incremental elastic modulus.

annular aorta hides under the ventricular outflow tract). This is the reason that some echocardiographic measurements for patients with aneurysms give small aortic diameters, when our usual criterion for surgical intervention in symptom-free patients is the presence an aneurysm of 5 to $5.5 \mathrm{~cm}$ or greater diameter.

\section{Aortic Wall Engineering Characteristics}

From the six epiaortic echocardiographic measurements, a complete mechanical profile of the aorta was constructed. The engineering characteristics calculated, and their general significance, are as follows: (1) Distensibility refers to the capacity of the vessel wall to dilate during changes in intraluminal pressure. Vessel wall distensibility is directly related to elastin and collagen content and their structural characteristics. At a more elemental level, distensibility reflects the absorbance of energy and resultant elongation (strain) of distensible elements of the aortic wall during systole. During diastole, this energy is largely transferred back, as kinetic energy, to the fluid and cellular blood components, constituting the so-called "diastolic pumping action of the aorta." Distensibility is different at different levels of blood pressure (the stretch from $100-120 \mathrm{~mm} \mathrm{Hg}$ is different from that from $200-220 \mathrm{~mm} \mathrm{Hg}$ ). (2) Wall stress refers to the amount of pressure (force per unit of surface area) applied by the circulating, pressurized blood to the vessel wall. Small segments of vessels can be viewed as cylinders, so wall stress can be construed conceptually as either longitudinal (tending to elongate the cylinder) or circumferential (tending to make the cylinder wider). In the case of the aorta, circumferential wall stress is of major importance and thus is the component of wall stress on which we concentrated in this study. Wall stress must always be constrained by the wall strength of the aorta. Rupture or dissection occurs when wall stress reaches and surpasses wall strength. (3) $E_{\text {inc }}$ describes the amount of strain (deformation) that elastin and collagen can absorb for a specific stress (pressure). Thus this term describes the stress/strain relationship. The study of the stress/strain relationship, that is, the quantification of how much force is needed to produce a specific diameter increase, is of great importance. High $\mathrm{E}_{\mathrm{inc}}$ values essentially imply that in a prerupture phase applied force tends to cause less deformation (strain) simply because the aortic wall tissue has already been stretched to its maximum. At some point, an applied stress may exceed the inherent structural strength of the aortic wall. If this transition can be predicted, catastrophic aortic rupture or dissection can be avoided by timely surgical intervention.

\section{Calculation of Mechanical Properties}

The equations used to calculate the mechanical properties in this study are given in Appendix E1.

\section{Statistical Analysis}

Statistical evaluation was performed with the use of the commercially available biostatistical Primer of Biostatistics software by Stanton A. Glantz, PhD (McGraw-Hill Health Professions Division, New York, NY). Data are presented either as mean or mean \pm SEM. Best fit lines were calculated with the least-squares method. The Fisher exact test, $t$ test, 1-way analysis of variance, and Kruskal-Wallis test were implemented as needed to define correlations between normal and aneurysm groups.

TABLE 2. Comparisons of mechanical parameters between normal ascending aortas and ascending aortic aneurysms

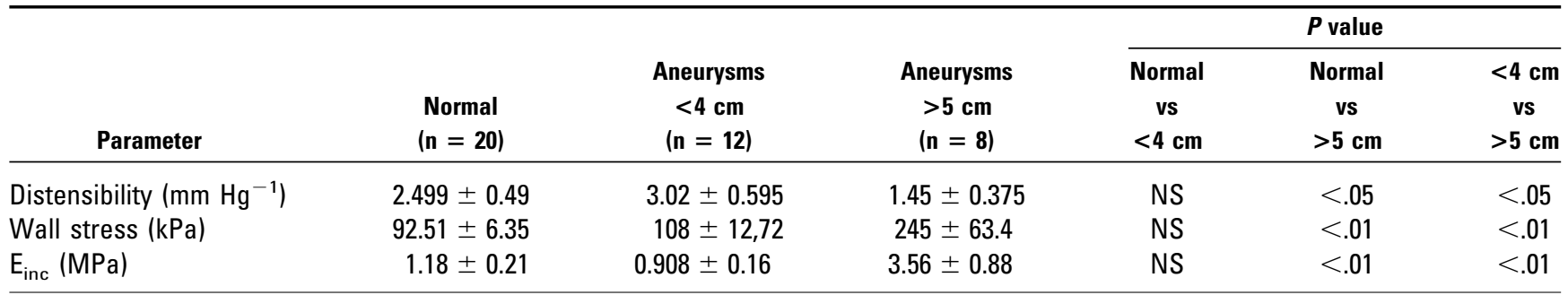

All data are mean \pm SEM. NS, Not significant; $E_{\text {inc }}$ incremental elastic modulus. 


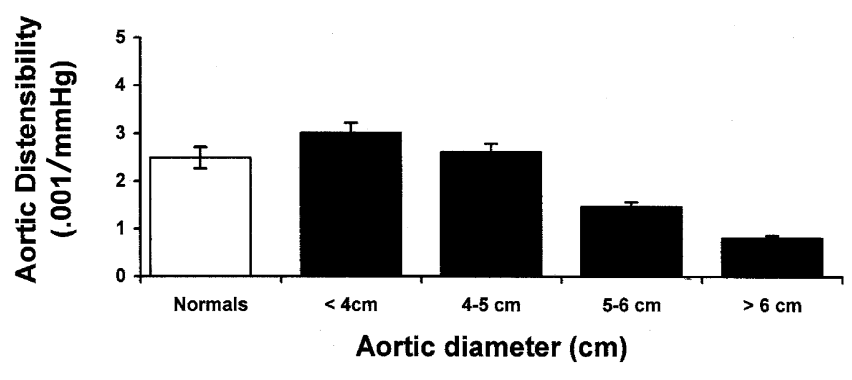

Figure 1. Distensibility values in normal aortas and aortic aneurysms of different diameters. Distensibility of ascending aortic aneurysms decreases rapidly as diameter increases, to very low values at dimensions greater than $6 \mathrm{~cm}$.

\section{Results}

Results for all three parameters-distensibility, wall stress, and $\mathrm{E}_{\text {inc }}$ - are presented in Tables 1 and 2. Wall stress was much greater for aneurysms than for normal aortas $(157$ vs $92.5 \mathrm{kPa}, P<.01)$. $\mathrm{E}_{\text {inc }}$ was also much higher for aneurysms than for normal aortas (1.93 vs 1.18 MPa, $P<.05)$. Distensibility did not differ until we separated small $(<4 \mathrm{~cm})$ from large $(>5 \mathrm{~cm})$ aneurysms (Tables 1 and 2). As is seen in Table 2, all parametersincluding distensibility, wall stress, and $\mathrm{E}_{\text {inc }}$ - had deteriorated in the larger aneurysms $(P<.01$ to $P<.05)$. As can be seen from both tables, large aneurysms were stiffer (lower distensibility), experienced higher wall stress, and had a poorer (higher) $\mathrm{E}_{\text {inc }}$.

\section{Distensibility}

Figures 1 and E1 display aortic distensibilities in normal and aneurysmal aortas. It can be noted that normal aortas and very small aneurysms had similar distensibilities (2.499 $\pm 0.49 \mathrm{~mm} \mathrm{Hg}^{-1}$ vs $3.02 \pm 0.595 \mathrm{~mm} \mathrm{Hg}^{-1}, P$ not significant; Table 2). Note that as aneurysm size increased, aortic distensibility decreased progressively (in aneurysms with diameter $<4 \mathrm{~cm}$ vs those with diameter $>5 \mathrm{~cm}, 3.02 \pm$

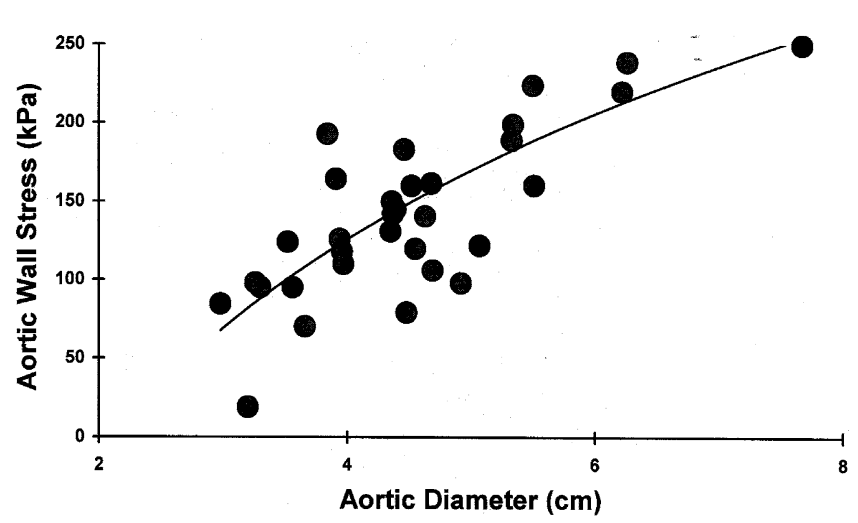

Figure 2. Wall stress in aortic aneurysms.

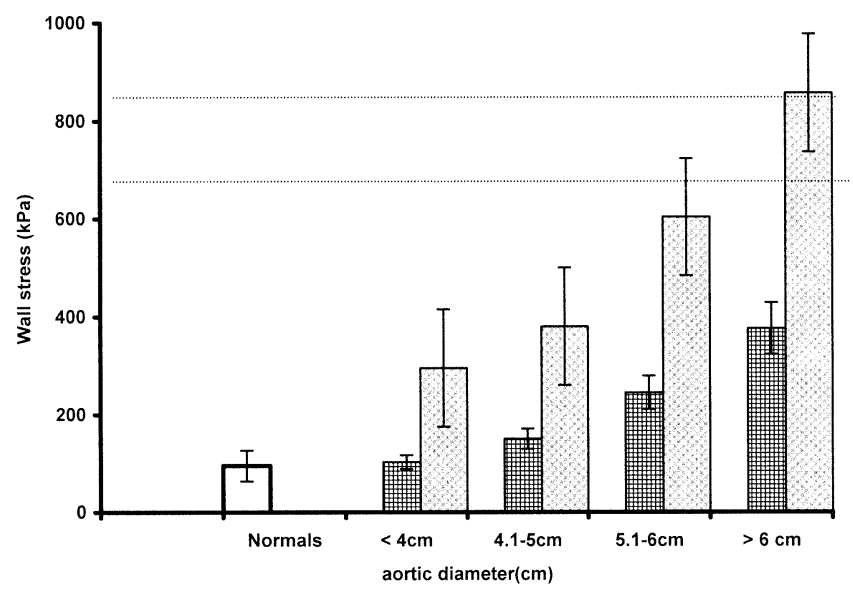

Figure 3. Exponential relationship between wall stress and aneurysm size in ascending aortic aneurysms. Dark bars represent blood pressure of $100 \mathrm{~mm} \mathrm{Hg}$; light bars represent blood pressure of $200 \mathrm{~mm} \mathrm{Hg}$. Lines at 800 to $1000 \mathrm{kPa}$ represent range of maximum tensile strength of human aorta. Bar heights represent mean; error bars represent SEM.

$0.595 \mathrm{~mm} \mathrm{Hg}^{-1}$ vs $1.45 \pm 0.375 \mathrm{~mm} \mathrm{Hg}^{-1}, P<.05$; Table 2). By $6 \mathrm{~cm}$ aortic diameter, distensibility was extremely low. Aortas of this dimension were almost completely inelastic and nondistensible.

\section{Wall Stress}

The mean wall stress value for normal aortas $(92.51 \pm 6.35$ $\mathrm{kPa})$ was significantly lower than that for ascending aortic aneurysms $(157.8 \pm 18.76 \mathrm{kPa}, P<.01$; Table 2$)$. Wall stress is displayed more fully in Figure 2. Table 1 shows that as aneurysm size increased, wall stress values increased dramatically. This is seen diagrammatically in the scatter plot of Figure 2, which emphasizes the rise in wall stress with increasing aortic size. Ascending aortic aneurysms with a diameter of at least $5 \mathrm{~cm}$ had significantly higher wall

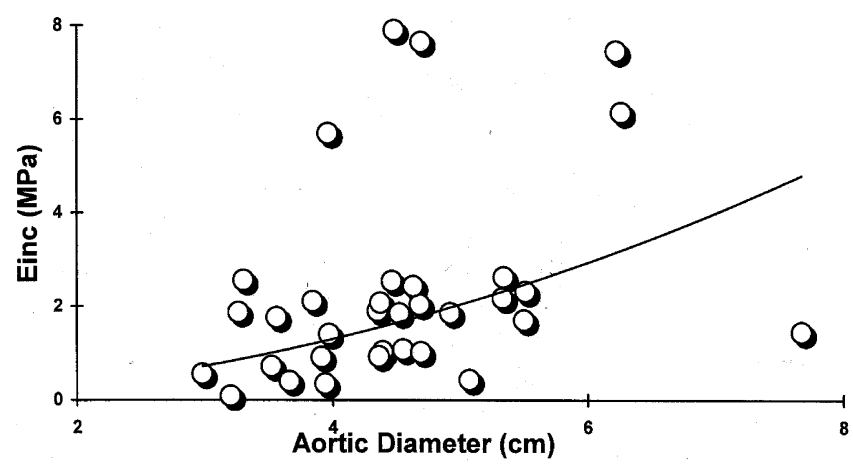

Figure 4. Relationship between $E_{i n c}$ and aortic diameter in ascending aortic aneurysms $(n=33)$. $E_{\text {inc }}$ rises as aortic diameter increases. 


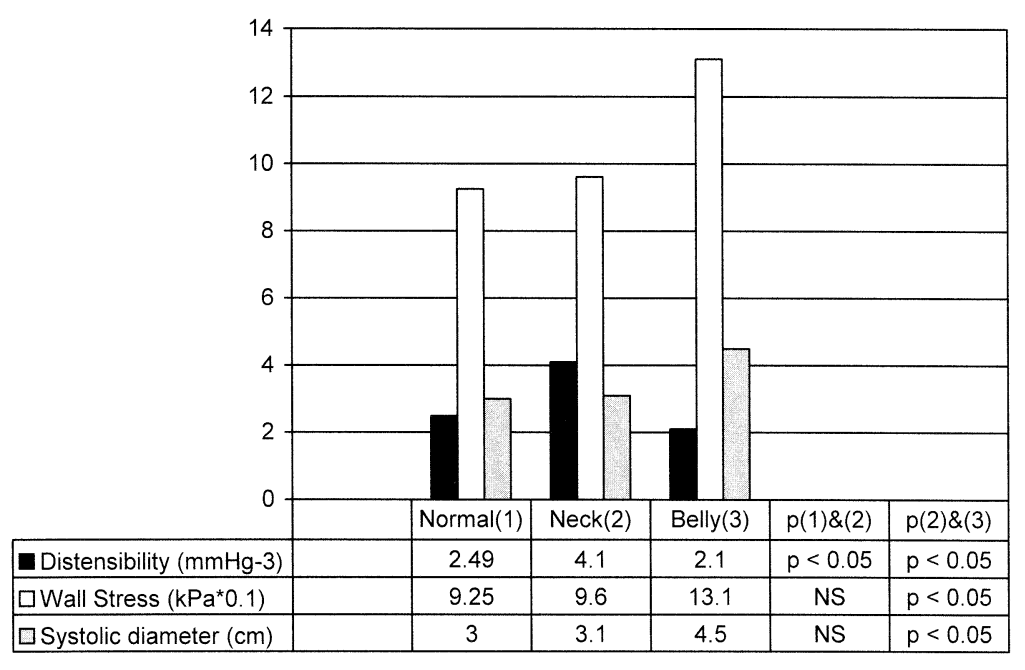

Figure 5. Comparison of distensibility (and wall stress) at neck and belly of ascending aortic aneurysms. Bar heights represent mean.

stress values than did smaller aneurysms and normal aortas $(P<.05)$. Ascending aneurysms with diameter greater than $6 \mathrm{~cm}$ had a mean wall stress of $376 \pm 146.6 \mathrm{kPa}$ at a blood pressure of $100 \mathrm{~mm} \mathrm{Hg}$. At a mathematically extrapolated systolic blood pressure of $220 \mathrm{~mm} \mathrm{Hg}$, which in real life corresponds to strenuous activity, an episode of emotional crisis, or a hypertensive crisis of other etiology, aneurysms of this size $(>6 \mathrm{~cm})$ would experience a wall stress value of $857 \pm 290.8 \mathrm{kPa}$. The corresponding values of wall stress for blood pressures of $100 \mathrm{~mm} \mathrm{Hg}$ and $220 \mathrm{~mm} \mathrm{Hg}$ are shown in Figure 3. The extremely serious implications of wall stresses in this range are explored in the Discussion section.

\section{Incremental Elastic Modulus}

$\mathrm{E}_{\text {inc }}$ mean values in ascending aortic aneurysms were significantly higher than in normal aortas $(1.93 \pm 0.88 \mathrm{MPa}$ vs $1.18 \pm 0.21 \mathrm{MPa}, P<.05$; Table 1$)$. Within ascending aortic subgroups of different sizes, aneurysms less than 4 $\mathrm{cm}$ in diameter had significantly lower $\mathrm{E}_{\mathrm{inc}}$ values than those with diameter higher than $5 \mathrm{~cm}(0.908 \pm 0.16 \mathrm{MPa}$ vs $3.56 \pm 0.88 \mathrm{MPa}, P<.01$; Table 2 ), implying that larger ascending aortic aneurysms have already been stretched near their limits. $\mathrm{E}_{\mathrm{inc}}$ increased progressively with each rise in aneurysm diameter (Table 1 and Figure 4).

\section{Distensibility and Wall Stress Evolution in the Neck of the Aneurysm}

In 15 of 33 patients with aneurysms, sequential application of the epiaortic probe was performed at both the neck and the belly of the aneurysm, permitting valuable calculation of mechanical parameters at two sites within the same patient. These results are shown in Figure 5. During epiaortic imaging, the neck was chosen as an area of smaller (often normal) aortic diameter beyond the most aneurysmal por- tion, not as the transition zone between aneurysmal and normal aorta.

Distensibility in the neck of the aneurysm was higher than in normal aortas $\left(4.1 \mathrm{~mm} \mathrm{Hg}^{-1}\right.$ vs $\left.2.49 \mathrm{~mm} \mathrm{Hg}^{-1}\right)$, consistent with an inherent connective tissue deficiency. Note that this is a valuable comparison, because aortic diameter at the neck of the aneurysms was similar to that of the normal aortas $(3.1 \mathrm{~cm}$ vs $3.0 \mathrm{~cm})$. Also, distensibility at the neck was higher than at the belly of the aneurysm (4.1 vs $2.1 \mathrm{~mm} \mathrm{Hg}^{-1}$ ), reflecting within a single patient the deterioration of mechanical properties that accompanies aortic dilatation. Wall stress was higher at the belly than at the neck of the aneurysms.

\section{Discussion}

This investigation contributes in two ways to our understanding of the pathophysiology and appropriate management of ascending thoracic aortic aneurysmal disease. First, this study expands our understanding of the mechanical basis for the adverse biologic behavior of ascending aortic aneurysms. Second, this study suggests a means of refining our criteria for surgical intervention in ascending thoracic aortic aneurysmal disease.

This study demonstrates that echocardiographic imaging can provide meaningful assessment of the mechanical characteristics of the human ascending aorta. Specifically, through these means, we have shown that (1) large aneurysms are stiffer than normal aortas (lower distensibility and higher elastic modulus), (2) large aneurysms experience dramatically increased wall stress, (3) within the same patient mechanical characteristics are better maintained at the neck than in the belly of the aneurysm, and (4) large aneurysms in a physiologic range of blood pressure found in daily life exhibit wall stress that equals or exceeds the 
known ultimate tensile strength of aortic tissue. These findings indicate a marked mechanical deterioration of the structural properties of the aortic wall in large ascending aortic aneurysms.

Okamoto and associates ${ }^{11}$ have shown that the intrinsic mechanical properties of the ascending aorta are affected principally by age rather than by clinical diagnosis. Age affects mechanical properties by two means: by element fatigue (the accumulated total amount of systolic/diastolic movements of the aortic wall) and by age-related changes in wall composition. In our study the age factor was obviated because age was identical between normal and aneurysm groups.

We were intrigued to discover a striking correlation between this study of the mechanical properties of the aneurysmal human ascending aorta and our previous studies on the natural behavior of aortic aneurysms on different diameters. Specifically, our previous clinical studies had shown that when the aortic diameter reaches $6 \mathrm{~cm}$, the risk of catastrophic acute events (rupture or dissection) increases dramatically. It is for this reason that we have previously recommended a diameter criterion of $5.5 \mathrm{~cm}$ for preventive surgical extirpation of the aneurysmal ascending aorta.

In this study of the mechanics of ascending aortic aneurysm, we found that the mechanical properties of the human aorta deteriorated dramatically at precisely the same diameter of $6 \mathrm{~cm}$. At this size, the aorta became essentially a nondistensible tube (Figures 1 and E1.) As a correlate, at this level of nondistensibility at the same $6-\mathrm{cm}$ size, wall stress experienced in the aorta rapidly approached the previously known values of ultimate tensile strength of aortic wall tissue (Figure 3.)

In an important recent study, Vorp and colleagues ${ }^{12}$ mechanically stretched tissue strips from ascending aortic aneurysms obtained at surgery to the point of mechanical failure. They determined the maximum tensile strength of aneurysmal ascending aortic tissue to be approximately $1000 \mathrm{kPa}$. This value is very close to the $857 \pm 290 \mathrm{kPa}$ we calculated for large ascending aortic aneurysms at an ambient blood pressure of 200 to 220 $\mathrm{mm} \mathrm{Hg}$. On the basis of our data and those of Vorp and colleagues, ${ }^{12}$ one can conclude that in aneurysms $6 \mathrm{~cm}$ or more in diameter a sudden rise in blood pressure can create wall stress values that equal or exceed the breaking point of the aneurysm wall. This scenario of an enlarged aorta subject to wall stress near the maximum shear stress of human tissue sets the stage for catastrophic aortic events on the precipitous rises in blood pressure that form part of everyday life. ${ }^{13}$

We believe that the observation of mechanical deterioration at $6 \mathrm{~cm}$ in a way explains the malignant behavior seen clinically at this same dimension. Because the aorta becomes nondistensible at $6 \mathrm{~cm}$, all the force of cardiac contraction can no longer be dissipated in enlarging the aorta but rather increases the stress in the aortic wall isometrically, leading to rupture or dissection. Thus engineering analysis and clinical observations dovetail perfectly. The fact that aortic wall stress calculated in our patients at these dimensions reaches the values for ultimate tensile strength of human ascending aortic aneurysms provides additional strong evidence in favor of preventive surgical extirpation of the aneurysmal ascending aorta at a criterion size smaller than $6 \mathrm{~cm}$.

Recent findings in the molecular biology of the aortic wall may well explain the mechanism of deterioration of the mechanical properties of the aortic wall. It is becoming increasingly evident in the abdominal aorta that increased proteolysis contributes to degradation of the cellular and interstitial components of the aortic wall in patients with aneurysms. ${ }^{14,15}$ Similarly, we have recently shown ${ }^{16,17}$ that certain matrix metalloproteinases (MMP-1 and MMP-9) are upregulated, and their inhibitors (TIMP-1) are downregulated, in human thoracic aortic aneurysms with or without associated diseases. The overall proteolytic equilibrium (MMP-9/TIMP-1 ratio) is also significantly unbalanced toward the side of increased proteolysis in patients with aneurysms. The degradation of fibrillin, elastin, and collagen as a consequence of such proteolytic activity probably underlies the mechanical deterioration of the aorta that this investigation documents.

A limitation of this study is the fact that measurements were obtained by epiaortic echocardiography performed at the time of predetermined aortic replacement. It remains to be demonstrated that we can obtain similarly reliable data through transthoracic or transesophageal echocardiography. Such noninvasive determination of mechanical characteristics would be necessary to enable mechanical properties to be used in preoperative decision making. Another limitation is that the differences in mechanical properties between normal and aneurysmal aortas may be due to purely mechanical factors (size) rather than to intrinsic tissue characteristics. Our measurements cannot conclusively differentiate these possibilities.

We are confident that as our knowledge of the mechanical properties of the aneurysmal human aorta increases, we will be able to predict the likelihood of rupture or dissection not only by measuring the diameter of the aorta as we do now but also by calculating, on the basis of echocardiography, its mechanical properties, including distensibility and wall stress. Such assessment should lead to increased safety of our patients by selecting for preemptive surgical extirpation, on the basis of accessible and reproducible biomechanical data, those individuals most at risk of rupture or dissection. 


\section{References}

1. Coady MA, Rizzo JA, Hammond GL, Mandapati D, Darr U, Kopf GS, et al. What is the appropriate size criterion for resection of thoracic aortic aneurysms? J Thorac Cardiovasc Surg. 1997;113:476-91.

2. Davies RR, Goldstein LJ, Coady MA, Tittle SL, Rizzo JA, Kopf GS, et al. Yearly rupture or dissection rates for thoracic aortic aneurysms: simple prediction based on size. Ann Thorac Surg. 2002;73:17-27.

3. Boudoulas H, Toutouzas PK, Wooley CF, editors. Functional abnormalities of the aorta. Armonk (NY): Futura; 1996.

4. Elefteriades JA. Preface. In: Elefteriades JA, Diseases of the aorta. Cardiol Clin. 1999; 17:xv-xvii.

5. Cheitlin MD. Aortic distensibility: does it have a role in the progression of aortic regurgitation? Boudoulas H, Toutouzas PK, Wooley CF, editors. Functional abnormalities of the aorta. Armonk (NY): Futura; 1996.

6. Fuster V, Andrews P. Medical treatment of the aorta I. In: Elefteriades JA, editor. Diseases of the aorta. Cardiol Clin. 1999;17:697-715.

7. Toutouzas P. Medical treatment of the aorta II. In: Elefteriades JA, editor. Diseases of the aorta. Cardiol Clin. 1999;17:717-37.

8. Bonapace S, Rossi A, Cicoira M, Franceschini L, Golia G, Zanolla L, et al. Aortic distensibility independently affects exercise tolerance in patients with dilated cardiomyopathy. Circulation. 2003;107:1603-8.

9. Wilson KA, Lee AJ, Lee AJ, Hoskins PR, Fowkes FG, Ruckley CV, et al. The relationship between aortic wall distensibility and rupture of infrarenal abdominal aortic aneurysm. J Vasc Surg. 2003;37:112-7.

10. Vorp DA, Raghauer ML, Webster MV. Mechanical wall stress in abdominal aortic aneurysm: influence of diameter and asymmetry. $J$ Vasc Surg. 1998:27:632-9.
11. Okamoto RJ, Xu H, Kouchoukos NT, Moon MR, Sundt TM 3rd. The influence of mechanical properties on wall stress and distensibility of the dilated ascending aorta. J Thorac Cardiovasc Surg. 2003;126:84250 .

12. Vorp DA, Schiro BJ, Ehrlich MP, Juvonen TS, Ergin MA, Griffith BP. Effect of aneurysm on the tensile strength and biomechanical behavior of the ascending aorta. Ann Thorac Surg. 2003;75:1210-4.

13. Elefteriades JA, Hatzaras I, Tranquilli MA, Elefteriades AJ, Stout R, Shaw RK, et al. Weight lifting and rupture of silent aortic aneurysms [letter]. JAMA. 2002;290:2803.

14. Newman KM, Ogata Y, Malon AM, Irizarry E, Gandhi RH, Nagase H, et al. Identification of matrix metalloproteinases 3 (stromelysin-1) and 9 (gelatinase B) in abdominal aortic aneurysm. Arterioscler Thromb. 1994;14:1315-20.

15. Longo GM, Xiong W, Greiner TC, Zhao Y, Fiotti N, Baxter TB. Matrix metalloproteinases 2 and 9 work in concert to produce aortic aneurysms. J Clin. Invest. 2002;110:625-32.

16. Koullias G, Ravichandran P, Korkolis DP, Rimm DL, Elefteriades JA. Increased tissue microarray matrix metalloproteinase expression favors proteolysis in thoracic aortic aneurysms and dissections. Ann Thorac Surg. 2004;78:2106-10.

17. Koullias G, Korkolis DP, Ravichandran P, Psyrri A, Hatzaras I, Elefteriades JA. Tissue microarray detection of matrix metalloproteinases, in diseased tricuspid and bicuspid aortic valves with or without pathology of the ascending aorta. Eur J Cardiothorac Surg. 2004;26: 1098-103.

\section{The Journal of Thoracic and Cardiovascular Surgery Conflict of Interest Policy}

To assure fairness to authors submitting work for consideration in The Journal of Thoracic and Cardiovascular Surgery, a mechanism exists for managing conflicts of interest. The editor and each of the section editors complete a "Conflict of Interest" form that identifies any and all relationships with commercial and other academic entities. When the editor has a potential conflict because of a relationship with another entity or author, the editor appoints an alternate editor from among the section editors or editorial board members who assumes the entire responsibility for final decisions on the manuscript in question. The editor does not read the reviews that are submitted nor engage in discussing the manuscript prior to the final decision. When the conflict of interest involves a section editor, a "guest section editor" is appointed who fills the role normally played by the conflicted section editor. All members of the editorial board and reviewers are asked to indicate any conflict of interest when they agree to review a manuscript. 


\section{Appendix E1}

Equations used in calculation of mechanical properties are as follows.

Distensibility. Distensibility (Dist) at a pressure $P$ is calculated as follows: $\operatorname{Dist}\left(\mathrm{P}_{\text {syst }}\right)=1 / \mathrm{LCSA}_{\text {syst }} \times \delta \mathrm{LCSA} /$ $\delta \mathrm{P}$, where $L C S A$ is the lumen cross-sectional area, $\delta L C S A$ is the difference of the LCSA between systole (syst) and diastole, and $\delta P$ is the difference between systolic and diastolic blood pressures. LSCA (assuming that the ascending aorta is circular) is $\pi \mathrm{r}^{2}$, or $\pi(\mathrm{d} / 2)^{2}$. Distensiblity is measured in $\mathrm{mm} \mathrm{Hg}^{-1}$.

Wall stress. Wall stress (WS) is measured at peak systole. $\mathrm{WS}(\sigma)$ at a blood pressure $P$ is expressed from the following equation: $\mathrm{WS}(\sigma)(\mathrm{P})=2 \mathrm{LCSA} \times \mathrm{P}_{\text {syst }} / M C S A$, where $M C S A$ is the surface area of the aortic wall cross sectional area, the aortic wall thickness $\left(\mathrm{W}_{\text {syst }}\right)$ multiplied by the aortic perimeter $(2 \pi \mathrm{r})$. Wall stress is measured in pascals $\left(1\right.$ Pascal $=1 \mathrm{~N} / \mathrm{m}^{2}$ ) and usually expressed in kilopascals $\left(1 \mathrm{kPa}=10^{3} \mathrm{~Pa}\right)$.

Incremental elastic modulus $\left(\boldsymbol{E}_{\text {inc }}\right) . \mathrm{E}_{\mathrm{inc}}$ at a specific blood pressure $P$ is defined as the tangent of the stress/strain curve of the aortic wall and is expressed by the following equation: $\mathrm{E}_{\text {inc }}=3 / \operatorname{Dist}(\mathrm{P}) \times(1+\mathrm{LCSA} / \mathrm{MCSA}) . \mathrm{E}_{\mathrm{inc}}$ is measured in pascals and usually expressed in megapascals $\left(1 \mathrm{MPa}=10^{6} \mathrm{~Pa}\right)$. 


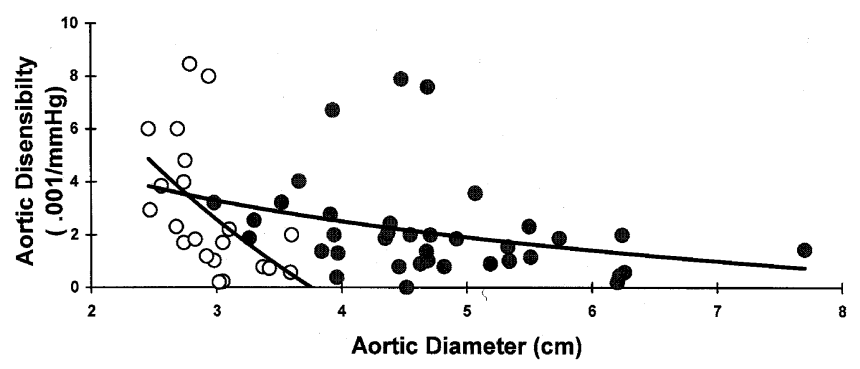

Figure E1. Relationship between aortic distensibility and aortic diameter in normal aortas ( $\mathrm{n}=20$, white circles) and ascending aortic aneurysms ( $n=33$, gray circles). 